\title{
Significance of a low serum ferritin level in elderly in-patients
}

\author{
E. Joosten ${ }^{1}$, L. Dereymaeker ${ }^{1}$, W. Pelemans ${ }^{1}$ and M. Hiele ${ }^{2}$ \\ Department of Internal Medicine, Division of Geriatric ${ }^{1}$ Medicine and ${ }^{2}$ Gastroenterology, University \\ Hospitals, K.U. Leuven, Belgium
}

Summary: Iron deficiency, defined as a serum ferritin level less than or equal to $50 \mu \mathrm{g} / \mathrm{l}$ was found in $28(11 \%)$ of 252 consecutive elderly in-patients (mean age 81 years). Sixteen among them were anaemic and only five had a microcytic anaemia. In a separate study, 15 anaemic and 13 non-anaemic iron-deficient elderly in-patients were investigated in order to evaluate the prevalence of gastrointestinal symptoms and lesions in both groups. In nine of the anaemic and seven of the non-anaemic patients a potential cause for the iron deficiency was established. Most anaemic and non-anaemic patients lacked the symptoms described as suggestive of underlying gastrointestinal pathology. Thus, a ferritin level less than or equal to $50 \mu \mathrm{g} / \mathrm{l}$ justifies a gastrointestinal investigation if the general condition allows for it as well in anaemic as in non-anaemic elderly hospitalized patients. Therefore, serum ferritin should be part of the routine biochemical investigation of elderly in-patients.

\section{Introduction}

Anaemia is a common problem in the elderly and next to the anaemia of chronic disorders, iron deficiency is its second most common cause in an hospitalized elderly population. ${ }^{1}$ Recently published clinical studies on iron deficiency emphasized the value of the serum ferritin level as the main diagnostic index. ${ }^{2-4}$ In a general geriatric population, Guyatt and coworkers demonstrated that a serum ferritin level below $45 \mu \mathrm{g} / \mathrm{l}$ was the best cut-off limit of iron deficiency in this group. ${ }^{3} \mathrm{We}$ confirmed those data and found that a serum ferritin level less than or equal to $50 \mu \mathrm{g} / 1$ was strongly suggestive of iron deficiency. ${ }^{4}$ The aims of the present study were to determine the prevalence of iron deficiency in a consecutive elderly hospitalized group and to examine to what extent gastrointestinal investigation would reveal a potential causative lesion in nonanaemic as well as in anaemic iron-deficient patients.

\section{Patients and methods}

The first study group (group A) comprised 252 consecutive elderly patients aged 70 years and older, and referred to the acute geriatric unit of our

Correspondence: E. Joosten, M.D., Division of Geriatric Medicine, University Hospitals Leuven, Brusselsestraat 69, B-3000 Leuven, Belgium.

Accepted: 9 November 1992 hospital. Peripheral blood counts were analysed on a Coulter S Plus IV and a radioimmunoassay (Becton-Dickinson) was used to assess ferritin in serum. The vitamin $B_{12}$ and folate in red blood cell levels of these patients are reported elsewhere. ${ }^{5}$ Anaemia was defined according to the World Health Organization criteria (haemoglobin $<13.0 \mathrm{~g} / \mathrm{dl}$ for mean and $<12.0 \mathrm{~g} / \mathrm{dl}$ for women). Iron deficiency was diagnosed as a serum ferritin level less than or equal to $50 \mu \mathrm{g} / \mathrm{l}^{4}$

In order to assess the efficiency of a gastrointestinal investigation in anaemic as well as in nonanaemic elderly (aged 70-94 years) in-patients with iron deficiency, 13 consecutive non-anaemic patients were compared with another group of 15 consecutive anaemic patients (group B) in a separate study. They all had a serum ferritin level less than $50 \mu \mathrm{g} / 1$ and were identified over approximately the same period. None of these 28 patients belonged to the former group of 252 elderly patients. The following exclusion criteria were applied: a confirmed malignancy upon admission; an obvious cause of blood loss such as trauma, recent surgery, urological pathology; follow-up of a previously diagnosed gastrointestinal lesion (either benign or malignant); known primary haematological disease; mental impairment or a poor general condition which might interfere with an adequate investigation. Patients with a low serum ferritin and normal haemoglobin level who developed anaemia due to overt gastrointestinal 
blood loss during the first days of hospitalization were also excluded from the non-anaemic group. None of the patients included in the study was being treated with iron or had a blood transfusion during the last year. A clinical history including documentation of non-steroidal anti-inflammatory drug (NSAID) ingestion and previous surgery was obtained. Complaints were divided in upper (dysphagia, heartburn, nausea, vomiting, epigastric pain) and lower (altered bowel habits, diarrhoea or constipation of recent onset, rectal bleeding or melaena, abdominal distention or lower abdominal pain) gastrointestinal symptoms. Anorexia, weight loss without concomitant symptoms and chronic constipation were considered as non-specific.

Serum iron and total iron-binding capacity were measured with an autoanalyser procedure (Technicon). All iron-depleted patients underwent a full physical examination and an upper gastrointestinal endoscopy. Colonic investigation was carried out in 24 patients; a barium enema examination in 17, a colonoscopy in three and both examinations in four patients. Hiatus hernia and macroscopic findings of gastritis without overt bleeding or other significant upper gastrointestinal lesions and solitary colonic diverticulosis were not considered as a cause of iron deficiency. In the four remaining patients, a colonic investigation was not performed or revealed inadequate information. Rectoscopy and barium enema of the small bowel were performed when clinically indicated and were excluded from further analysis.

Continuous variables were compared with the Student $t$-test or the Mann-Whitney test. Analysis of categorical data was done by the two-tailed Fischer exact test.

\section{Results}

Figure 1 shows the relation between serum ferritin and haemoglobin in 252 consecutive elderly inpatients (group A) older than 70 years (110 males and 142 females, mean age 81 years, range 70-96 years). A serum ferritin level below or equal to $50 \mu \mathrm{g} / \mathrm{l}$ was found in nine men and 19 women $(11 \%$ of the total group). Sixteen (57\%) of them were anaemic and seven $(25 \%)$ had a mean corpuscular volume below $80 \mathrm{fl}$ of whom two were not anaemic.

Table I summarizes the haematological data of the 15 anaemic and 13 non-anaemic iron-deficient patients of group B who had a gastrointestinal investigation. Serum ferritin and total iron binding capacity did not differ significantly between both groups. Five of the anaemic though none of the non-anaemic patients had a mean corpuscular volume below $80 \mathrm{fl}$. All but one of the non-anaemic patients had a normal haemoglobin level upon discharge without iron supplementation during

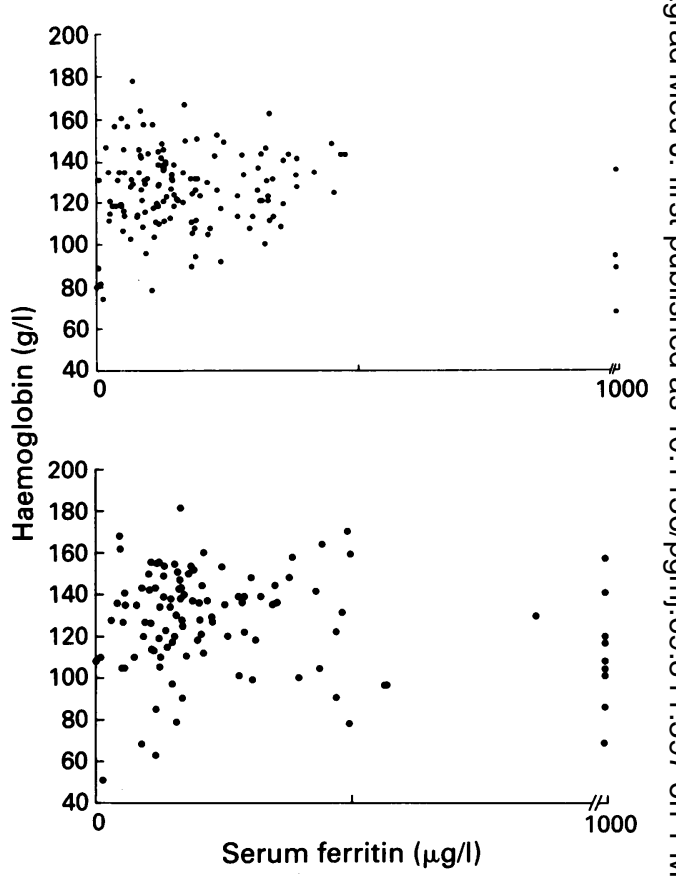

Figure 1 Relation between serum ferritin and haemoglobin in 252 elderly consecutive in-patients (top panel: $\overrightarrow{0}$ 142 women, lower panel: 110 men).

hospitalization. The other patient died because of a septic shock complicated with anaemia.

Table II shows the findings of the gastrointestinal exploration of the patients of group B. In nine of the 15 anaemic and in seven of the 13 nonanaemic patients $(P=\mathrm{NS})$, a potential cause for gastrointestinal blood loss was found including two patients taking NSAID though without 3 specific gastrointestinal lesions. NSAID were useddaily by four and warfarin by one patient. In three 3 . of these five patients, a specific upper gastrointes- $\hat{\circ}$. tinal lesion was demonstrated but none of them had colonic lesions.

Table III represents the association between the clinical symptoms and gastrointestinal lesions (on음 endoscopy and radiography) in group B. Nineteen of the 28 patients had no upper or lower gastro- $\sigma$ intestinal symptoms though a gastrointestinal N lesion on endoscopy or radiography was found inN eight and one patient without a visible gastrointes- $-\sigma$ tinal lesion used NSAID. Upper gastrointestinal symptoms were present in three each of the? anaemic $(20 \%)$ and the non-anaemic $(23 \%)$ subjects $(P=\mathrm{NS})$. Lower gastrointestinal symptoms were present in only four of the 24 patients who $\overline{0}$ underwent a colonic assessment. Of the three $\overrightarrow{\mathbb{D}}$ patients with a colorectal carcinoma, only one had $\frac{?}{\mathbb{Q}}$ specific lower gastrointestinal symptoms. 
Table I Laboratory data in 15 anaemic and 13 non-anaemic elderly in-patients with a serum ferritin level $\leqslant 50 \mu \mathrm{g} / 1$

\begin{tabular}{lccc}
\hline & Anaemic & Non-anaemic & P value \\
\hline No. of patients (men/women) & $15(6 / 9)$ & $13(2 / 11)$ & \\
Age (years) & $83(3.5)$ & $82.5(5.5)$ & \\
Haemoglobin $(\mathrm{g} / \mathrm{dl})$ & $9.6(2.2)$ & $13.8(1.0)$ & \\
Mean corpuscular volume (fl) & $82(9)$ & $92(5)$ & 0.001 \\
Serum ferritin $(\mu \mathrm{g} / \mathrm{l})$ & $21(12)$ & $26(13)$ & 0.36 \\
Serum iron $(\mu \mathrm{g} / \mathrm{dl})$ & $40(31)$ & $67(27)$ & 0.02 \\
Total iron binding capacity $(\mu \mathrm{g} / \mathrm{dl})$ & $349(63)$ & $317(58)$ & 0.18 \\
\hline
\end{tabular}

Values other than number of patients are means $( \pm S D)$.

Table II Potential causes associated with iron deficiency in anaemic and non-anaemic elderly in-patients

\begin{tabular}{lcc}
\hline & Anaemic & Non-anaemic \\
\hline $\begin{array}{l}\text { Upper gastrointestinal lesions } \\
\text { Hiatus hernia with gastric erosions }\end{array}$ & 1 & \\
$\begin{array}{l}\text { Hiatus hernia with erosive } \\
\text { oesophagitis }\end{array}$ & 1 & \\
$\begin{array}{l}\text { Gastric erosions } \\
\text { Gastric/duodenal ulcer }\end{array}$ & $1 \dagger$ & $1^{*}$ \\
$\begin{array}{l}\text { Gastric cancer } \\
\text { Stomitis after gastric surgery }\end{array}$ & 1 & $2^{*}$ \\
$\quad$ Barrett oesophagus & 1 & 1 \\
$\begin{array}{l}\text { Colonic lesions } \\
\text { Colorectal carcinoma }\end{array}$ & $1 \S$ \\
$\begin{array}{l}\text { Use of non-steroidal anti- } \\
\text { inflammatory drugs without } \\
\text { gastrointestinal lesions }\end{array}$ & 2 & 1 \\
$\begin{array}{l}\text { No cause found } \\
\text { With colonic assessment } \\
\text { Without colonic assessment }\end{array}$ & 1 & 1 \\
\hline * and $\dagger$ represent a patient using a non-steroidal anti-inflammatory drug and \\
warfarin, respectively; $\S$ colonic investigation not available in this patient.
\end{tabular}

Table III Association of gastrointestinal symptoms with proven gastrointestinal lesions

\begin{tabular}{lcccc}
\hline & \multicolumn{2}{c}{ Anaemic } & \multicolumn{2}{c}{ Non-anaemic } \\
\hline & \multicolumn{3}{c}{ Upper gastrointestinal lesion } & $(n=28)$ \\
Upper gastrointestinal symptoms & + & - & + & - \\
Present & 2 & 1 & 2 & 1 \\
Absent & 4 & 8 & 3 & 7 \\
& \multicolumn{4}{c}{ Colonic lesion } \\
Lower gastrointestinal symtoms & + & - & + & - \\
Present & + & 2 & 1 & 1 \\
Absent & 0 & 10 & 0 & 8 \\
\hline
\end{tabular}

*four patients (one anaemic and three non-anaemic) without colonic assessment were excluded; $+=$ present; $-=$ absent. 


\section{Discussion}

There is a general agreement that serum ferritin is the single most important laboratory indicator of iron deficiency. ${ }^{2-4}$ In this study, $11 \%$ of an elderly population admitted to a geriatric hospital had iron deficiency, defined as a serum ferritin level lower than or equal to $50 \mu \mathrm{g} / 1$. Nearly half of them were not anaemic upon admission. Low serum ferritin with a normal haemoglobin level indicates iron storage depletion while both lower levels of both represent the typical iron deficiency anaemia. ${ }^{6}$ All studies searching for gastrointestinal causes of iron deficiency start from patients with anaemia combined with additional criteria of iron deficiency; $;^{1,7-11}$ the diagnostic yield of investigating iron deficient but non-anaemic elderly patients has not been examined so far.

The prevalence of gastrointestinal symptoms and lesions is equal in non-anaemic and anaemic patients with iron deficiency in our study. However, most patients deficient in iron have no history suggestive of a significant gastrointestinal lesion and their symptoms are atypical. ${ }^{9}$ A gastrointestinal cause, potentially responsible for the iron deficiency was identified in 16 of the $28(57 \%)$ patients; 14 had a radiologically or endoscopically proven gastrointestinal lesion and another two patients took NSAID though a gastrointestinal lesion was not identified. This results is slightly lower than other published series..$^{1,8-11}$ However, the criteria for significant gastrointestinal symptoms and potential lesions are rather stringent in this study. Colonoscopy and barium enema are the two most important colonic investigation techniques. Which one is to be preferred remains a matter of debate. ${ }^{12-14}$ Barium enema was chosen as the main technique for the initial evaluation of the

\section{References}

1. Joosten, E., Pelemans, W., Hiele, M., Noyen, J., Verhaeghe, R. \& Boogaerts, M. Prevalance and causes of anaemia in a geriatric hospitalized population. Gerontology 1992, 38: 111-117.

2. Burns, E.R., Goldberg, S.N., Lawrence, C. \& Wenz, B. Clinical utility of serum tests for iron deficiency in hospitalized patients. Am J Clin Pathol 1990, 93: 240-245.

3. Guyatt, G.H., Patterson, C., Ali, M. et al. Diagnosis of iron-deficiency anemia in the elderly. Am J Med 1990, 88: 205-208.

4. Joosten, E., Hiele, M., Ghoos, Y., Pelemans, W. \& Boogaerts, M.A. Diagnosis of iron-deficiency anemia in a hospitalized geriatric population. Am J Med 1991, 90: 653-654.

5. Joosten, E., Pelemans, W., Hiele, M. \& Goossens, W. Vitamine $B_{12}$ (cobalamine)-gebrek bij bejaarden (with English abstract). Ned Tijdschr Geneeskd 1990, 134: 652-656.

6. Cook, J.D. \& Skikne, B.S. Iron deficiency: definition and diagnosis. J Intern Med 1989, 226: 349-355.

7. Riley, J.W., Wilson, P.C. \& Grant, A.K. Double pathology as a cause of occult gastrointestinal blood loss. Br Med J 1981, 282: $626-627$. colon in this study because it causes less discomfort smaller neoplastic lesions, polyps and especially angiodysplasia might not have been recognized. $\cong$

No patient with a benign upper gastrointestinal $\stackrel{\leftarrow}{\leftarrow}$ lesion had significant colonic pathology; the three $\overrightarrow{\overrightarrow{\mathrm{s}}}$ patients with a colorectal cancer had a normalo upper gastrointestinal endoscopy. The occurrence $\frac{}{0}$ of colonic tumours was the same in non-anaemic $\overline{\bar{s}}$. iron-deficient patients as in anaemic iron-deficient $\widehat{\widetilde{\phi}}$ patients suggesting that colonic investigation is $\cong$ also indicated in iron-deficient patients without ${ }^{\infty}$ anaemia. However, these findings have to be $\vec{O}$ interpreted cautiously. The total population $\overrightarrow{ }$ investigated in this study is too small to evaluate ${ }_{\sigma}^{\omega}$ critically whether a colonic investigation is needed $\bar{Q}$ in those elderly patients with iron deficiency in 3 whom a benign upper gastrointestinal lesion is discovered, as suggested by others. ${ }^{7-9}$ Subse-

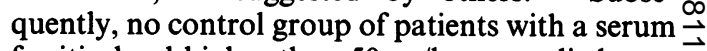
ferritin level higher than $50 \mu \mathrm{g} / 1$ was studied.

In conclusion, iron deficiency is a significant $\stackrel{\ominus}{\vartheta}$ problem in anaemic and non-anaemic elderly in-을 patients. Our findings provide some evidence that $\rightarrow$ upper and lower gastrointestinal investigations are $z$ appropriate in non-anaemic as well as in anaemic elderly in-patients with iron deficiency as far as a $\overrightarrow{0}$ therapeutical benefit might be expected. Therefore $\stackrel{\oplus}{\omega}$ serum ferritin level should be part of the routine biochemical investigation of the hospitalize elderly patient.

\section{Acknowledgement}

We thank R. Verhaeghe for his advice in preparing this manuscript.
8. Ward, M.C., Gundroo, D., Bailey, R.J., Mehta, T.V. \& Vallon, A.G. Effect of investigation on the management of elderly patients with iron deficiency anaemia. Age Ageing 1990, 19: 204-206.

9. Cook, I.J., Pavli, P., Riley, J.W., Goulston, K.J. \& Dent, O.F. Gastrointestinal investigation of iron deficiency anaemia. $\mathrm{Br}$ Med J 1986, 292: 1380-1382.

10. Croker, J.R. \& Beyon, G. Gastro-intestinal bleeding-A major cause of iron deficiency in the elderly. Age Ageing 1981, 10: $40-43$.

11. Calvey, H.D. \& Castleden, C.M. Gastrointestinal investigations for anaemia in the elderly: a prospective study. Age Ageing 1987, 16: 399-404.

12. Gurwitz, J.H., Noonan, J.P., Sanchez, M. \& Prather, W. Barium enemas in the frail elderly. Am J Med 1992, 92:41-44.

13. MacCarty, R.L. Colorectal cancer: the case for barium enema. Mayo Clin Proc 1992, 67: 253-257.

14. Bat, L., Pines, A., Shemesh, E. et al. Colonoscopy in patients aged 80 years or older and its contribution to the evaluation of rectal bleeding. Postgrad Med J 1992, 68: 355-358. 